\title{
ARTICLE
}

\section{Triclosan: Electrochemistry, Spontaneous Degradation and Effects on Double-Stranded DNA}

\author{
Elizaura Hyeda Carvalho Silva1 ${ }^{1}$, Ilanna Campelo Lopes ${ }^{1 *}$ (D), Evellin Enny Silva Bruzaca1 (iD, \\ Paulina Andréa Viana de Carvalho ${ }^{1,2}$ iD, Auro Atsushi Tanaka ${ }^{1,3 *}$ iD \\ ${ }^{1}$ Departamento de Química, Centro de Ciências Exatas e Tecnologia, Universidade Federal do Maranhão, \\ CEP 65080-805, São Luís, MA, Brazil \\ ${ }^{2}$ Instituto Federal de Educação, Ciência e Tecnologia do Maranhão, CEP 65363-000, Zé Doca, MA, Brazil \\ ${ }^{3}$ Instituto Nacional de Ciência e Tecnologia de Bioanalítica, Caixa Postal 6154, CEP 13083-970, Campinas, SP, \\ Brazil
}

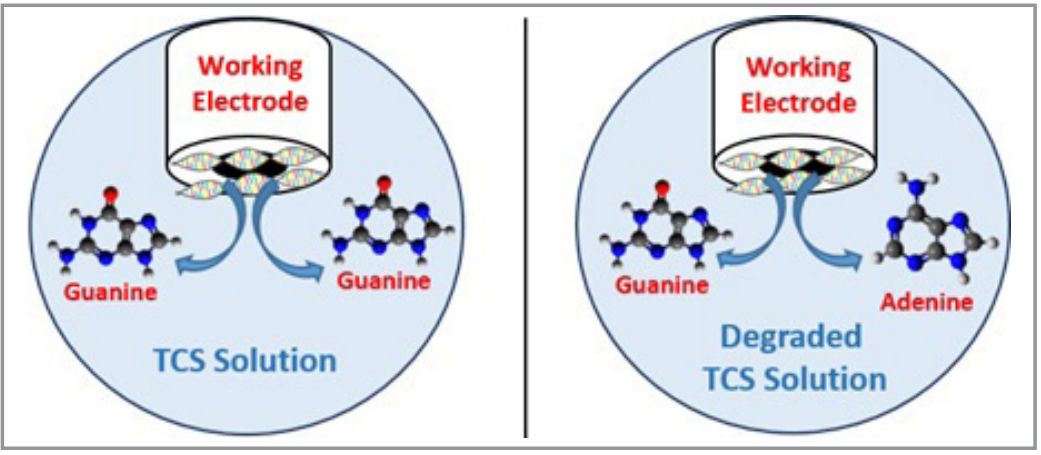

Triclosan (TCS) is an antiseptic agent widely used mainly in personal care products and an important contaminant, which degrades in the environment causing toxicity on health, including negative effects on DNA. In this context, an electrochemical investigation of TCS in aqueous solution was studied by voltammetric techniques. The TCS underwent irreversible oxidation in a $\mathrm{pH}$ dependent process, leading to the formation of two reversibly oxidized and $\mathrm{pH}$-dependent oxidation products. An oxidation mechanism for TCS and its oxidation products in neutral aqueous medium was proposed. Besides that, the TCS spontaneously degraded into supporting eletrolytes with $3.4 \leq \mathrm{pH} \leq 12.04$ over the incubation time and the degraded TCS in solution was detected by electrochemical and spectrophotometric techniques. A higher degradation of TCS was observed in alkaline medium. In addition, the interaction in situ of this antimicrobial with DNA was investigated using dsDNA incubated solutions and dsDNA electrochemical biosensor, by voltammetry. TCS and degraded TCS interacted with dsDNA causing the condensation of the double helix structure, release of guanine (by TCS and degraded TCS) and adenine (by degraded TCS) bases from dsDNA and a possible intercalation of degraded TCS in the polynucleotide chain. No dsDNA oxidative damage was detected.

Keywords: Triclosan; Contaminant degradation; Electrochemical oxidation; DNA interaction studies.

Cite: Silva, E. H. C.; Lopes, I. C.; Bruzaca, E. E. S.; de Carvalho, P. A. V.; Tanaka, A. A. Triclosan: Electrochemistry, Spontaneous Degradation and Effects on Double-Stranded DNA. Braz. J. Anal. Chem., 2021, 8 (31), pp 89-102. doi: http://dx.doi.org/10.30744/ brjac.2179-3425.AR-56-2020

Received 7 October 2020, Revised 3 December 2020, $2^{\text {nd }}$ time Revised 20 January 2021, Accepted 20 January 2021 , Available online 08 March 2021. 


\section{INTRODUCTION}

Pharmaceutical and personal care products have gained great attention in the last decades due to their persistent character in the environment [1]. Triclosan (TCS, 5-chloro-2-(2,4-dichlorophenoxy)-phenol) (Scheme 1) [2], a common contaminant in the environment [3], is a synthetic, lipid-soluble and broad spectrum antibacterial agent widely [4] used as addition ingredient in personal care products, medical, household, veterinary, and daily consumer products [5]. Among these, the chemical can be found in numerous professional and consumer goods [1] such as toothpaste and soaps [6], deodorants and cosmetics [7], kitchenware and plastic food containers [8].

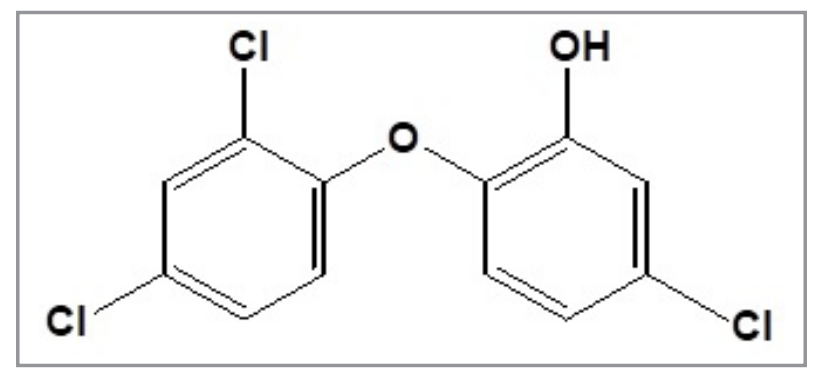

Scheme 1. Chemical structure of TCS.

TCS is quite harmful to the water environment as it has chronic toxicity [9]. It is known to undergo several types of partitioning and degradation process in the aquatic environment, including direct photochemical degradation [10]. When degraded, TCS can produce derivatives of great toxicity such as chlorophenols and dioxins, which are highly toxic to aquatic organisms (fish, algae, bacteria and protozoa) [11-13]. Furthermore, previous reports related that chloroform, extremely toxic intermediate product generated by TCS, was found in the free-chlorine-mediated oxidation of TCS drinking water [14]. It has also been reported that this pollutant can exert estrogenic and androgenic effects on the human body [15] and adverse effects on endocrine function in animals [16]. In the last few decades, it has been shown that TCS is biologically linked to antibiotics, leading to the possibility of inducing resistance to these drugs $[17,18]$. Evidence also pointed that exposure to an extreme amount of TCS can cause skin irritation, immunotoxic and neurotoxic reactions in humans [19].

The great concern on the toxicity of TCS and its metabolites on the environment and human health has led several researchers to study the negative effect of this biocide on DNA. TCS was recognised as a potential carcinogen by the United States Environmental Protection Agency (US EPA) in 2008 [20]. Degradation products from TCS are also known to be toxic and carcinogenic such as dioxin photoproducts [21] and chloroform which is classified by the US EPA as a probable human carcinogen [22].

Although there are several studies related to exposure to TCS and the adverse effects on human and environmental health, there is still a peculiar concern related to its harmful effects, mainly in relation to its carcinogenic potential, due to the lack of knowledge about the underlying mechanisms of these effects. TCS was exposed to HaCaT cells, an immortalized keratinocyte cell line from human skin, and evidenced TCS-induced genomic damage in human keratinocytes, leading to disturbances in proliferation rates [23]. When evaluating levels of global DNA methylation (GDM) in human hepatocytes, the results indicated that TCS reduced the levels of GDM and down-regulated the methylated DNA-binding domain proteins (MBD2 and MBD3), and MeCP2 gene expression by increasing 8-OHdG (8-hydroxy-2-deoxyguanosine) levels and inhibiting the mammalian DNA methyltransferase (DNMT1) activity in human hepatocellular carcinoma cells line (HepG2 cells) [24]. In addition, an investigation study of the association between TCS exposure and male fertility shown that this exposure can increase the percentage of sperm with abnormal morphology [25]. TCS is also associated with the development of liver tumours in rodents [26]. Additionally, this common biocide altered DNA methylation in zebrafish exposed during embryogenesis as well as related genes expression [27] and reduced significantly the reproduction of earthworms Eisenia 
fetida exposed to TCS, causing DNA damage and increase of expression levels of the Hsp70 gene of earthworms [28].

In view of the problem of the potentially toxic effects of TCS, several studies have been presented in the literature, using different methodologies for detection and determination of this compound [29-32]. Studies on degradation of TCS have also been reported as well as the investigation of the behaviour of antimicrobial agent in DNA. However, a complete methodology on electrochemical behaviour of TCS and its spontaneous degradation in aqueous solution has not been explored. Moreover, DNA based electrochemical biosensors became a very viable alternative for evaluating the interaction of this compound with DNA. They have been successfully utilized to investigate the interaction of small molecules with DNA and, compared to other methods, these sensors offer high sensitivity in the detection of small perturbations in the double helix chain and understanding the mechanisms of oxidative damage to DNA [33]. Our research group has used these biosensors in some previous studies to investigate the in situ interaction of anticancer drugs with DNA [34,35].

Thus, the aims of this work were (i) to study the electrochemical behaviour of TCS in aqueous solution by voltammetry (ii) to monitor the chemical degradation process of this antimicrobial agent in aqueous medium by voltammetric and spectrophotometric techniques and (iii) to investigate the interaction of TCS with DNA using DNA electrochemical biosensor and DNA incubated solutions.

\section{MATERIALS AND METHODS Reagents and solutions}

TCS (Irgasan, 5-chloro-2-(2,4-dichlorophenoxy)phenol, $\geq$ 97.0\% HPLC, CAS number: 3380-34-5), deoxyribonucleic acid sodium salt from calf thymus (dsDNA, type I, fibers, CAS number: 73049-39-5), polyguanylic acid potassium salt (poly[G], lyophilized powder, CAS number: 54684-83-2) and polyadenylic acid potassium salt (poly[A], CAS number: 26763-19-9) were purchased from Sigma-Aldrich.

Stock solutions of $0.1 \mathrm{mM}$ TCS were prepared in $\mathrm{NaOH}-\mathrm{H}_{2} \mathrm{O}(25: 75, \mathrm{v} / \mathrm{v})$ and $340 \mu \mathrm{g} \mathrm{mL}{ }^{-1} \mathrm{dsDNA}$ was prepared in deionized water. Real concentration of dsDNA was calculated by the multiplication of the experimentally UV-Vis spectrophotometric absorbance found by the conversion factor $\left(1 \mathrm{u} A_{260 \mathrm{~nm}}=50 \mu \mathrm{g}\right.$ $\mathrm{mL}^{-1}$ of dsDNA) [36]. Stock TCS solutions were kept wrapped in aluminium foil to protect them from the light. Both stock solutions were stored in the fridge $\left(4^{\circ} \mathrm{C}\right)$ until further utilization.

The supporting electrolyte solutions of different $\mathrm{pH}$ values used in the experiments were prepared according to the literature [37]: $\mathrm{CH}_{3} \mathrm{COOH} / \mathrm{CH}_{3} \mathrm{COONa}\left(\mathrm{pH} 3.4\right.$ to 5.4), $\mathrm{Na}_{2} \mathrm{HPO}_{4} / \mathrm{NaH}_{2} \mathrm{PO}_{4}(\mathrm{pH} 6.1$ to 8.1), $\mathrm{Na}_{2} \mathrm{~B}_{4} \mathrm{O}_{7} / \mathrm{NaOH}\left(\mathrm{pH} 9.2\right.$ to 10.2), $\mathrm{Na}_{2} \mathrm{HPO}_{4} / \mathrm{NaOH}(\mathrm{pH} 11.2)$ and $\mathrm{KCl} / \mathrm{NaOH}(\mathrm{pH} 12.0)$. The $\mathrm{pH}$ measurements were carried out using a Metrohm $827 \mathrm{pH}$ Lab pH-meter (Switzerland) with a Metrohm combined glass electrode.

All solutions were prepared using reagent-grade chemicals and purified water from a Millipore Milli- $Q$ system (resistivity $18.2 \mathrm{M} \Omega \mathrm{cm}$, conductivity $\leq 0.1 \mu \mathrm{S} \mathrm{cm}^{-1}$ ).

\section{Procedures}

\section{Electrochemical measurements}

Voltammetric experiments were performed using an Autolab PGSTAT 128N potentiostat in combination with GPES 4.9 Software (Eco Chemie B. V., Utrecht, The Netherlands). Cyclic voltammetry (CV), differential pulse (DP) and square wave (SW) voltammetry measurements were carried out using a glassy carbon electrode (GCE, $d=5.0 \mathrm{~mm}$ ) as working electrode, a Pt wire counter electrode and an $\mathrm{Ag} / \mathrm{AgCl}(3 \mathrm{M} \mathrm{KCl})$ electrode as reference, in a one-compartment electrochemical cell of $10 \mathrm{~mL}$ capacity.

The GCE was polished using diamond spray (particle size $1 \mu \mathrm{m}$, Kemet International Ltd, UK) before every electrochemical assay. After polishing, the electrode was rinsed thoroughly with Milli- $Q$ water. Following this mechanical treatment, the GCE was placed in buffer supporting electrolyte and various voltammograms were recorded until a steady state baseline voltammogram was obtained.

Buffer solutions were bubbled with high purity $\mathrm{N}_{2}$ (White Martins) for 10 minutes before $\mathrm{CV}$ measurements. 
DP voltammograms presented were baseline-corrected using the moving average application with a step window of $2 \mathrm{mV}$ included in the GPES version 4.9 software. This mathematical treatment improves the visualization and identification of peaks over the baseline without introducing any artefact. Nevertheless, this mathematical treatment of the original voltammograms was used in the presentation of all experimental voltammograms for a better and clearer identification of the peaks.

\section{Spectrophotometric measurements}

Spectrophotometric measurements were fulfilled in a spectrophotometer UV-Vis Varian Cary 50 (running with Cary Win UV software). Spectra were measured in a quartz glass cuvette (optical path of $1 \mathrm{~cm}$ ) from 200 to $400 \mathrm{~nm}$.

\section{TCS Degradation in solution}

The evaluation of TCS degradation in aqueous solution was studied spontaneously at different time periods at room temperature, by voltammetric and spectrophotometric measurements. For the first technique, $0.01 \mathrm{mM}$ TCS solutions (prepared in supporting electrolytes with $3.4 \leq \mathrm{pH} \leq 12.04$ and left to degrade chemically) were incubated for $24 \mathrm{~h}, 30$ and 64 days and then analysed. $0.0625 \mathrm{mM}$ TCS in buffer solutions $(3.4 \leq \mathrm{pH} \leq 9.20)$ were left to degrade for 30,64 and 70 days and after measured by UV-Vis spectrophotometry. After each analyse, for both techniques, degraded TCS solutions were transferred to glass flasks and stored until further utilization.

\section{TCS-DNA Interaction studies}

The interaction of DNA with TCS and degraded TCS was explored using dsDNA, poly[G] or poly[A] incubated solutions and dsDNA biosensor, and performed by DP voltammetry.

Incubated solutions - Solutions of $100 \mu \mathrm{g} \mathrm{mL}^{-1} \mathrm{dsDNA}$, poly[G] or poly[A] with $5 \mu \mathrm{M}$ TCS or degraded TCS were prepared and incubated in $0.1 \mathrm{M}$ acetate buffer $\mathrm{pH} 4.5$ at different time period: $0,24,48$ and 72 h (TCS-dsDNA; TCS-poly[G]; TCS-poly[A]) and 0, 24, 48, 72 e 96 h (degraded TCS-dsDNA; degraded TCS-poly[G]; degraded TCS-poly[A]). The degraded TCS solution was left to degrade in $0.1 \mathrm{M}$ acetate buffer $\mathrm{pH} 4.5$ for 40 days. DP voltammograms were recorded in the solutions above described after each incubation period. Control solutions of dsDNA, poly[G] or poly[A] in $0.1 \mathrm{M}$ acetate buffer pH 4.5 were also made and analysed under similar conditions as TCS and degraded TCS incubated with dsDNA, poly[G] or poly[A] solutions.

dsDNA biosensor - The dsDNA biosensor was prepared by dropping consecutively three aliquots of $50 \mu \mathrm{L}$ of $100 \mu \mathrm{gmL}^{-1}$ dsDNA solution in the electrode surface. The biosensor was dried under a constant flux of $\mathrm{N}_{2}$ and rinsed in deionised water. After that, it was immersed and left to incubate for 1, 24, 48, 72 and $96 \mathrm{~h}$ in $5 \mu \mathrm{M}$ degraded TCS (95 days of degradation in buffer $\mathrm{pH} 4.5$ ) in $0.1 \mathrm{M}$ acetate buffer $\mathrm{pH} 4.5$. For each incubation time a new dsDNA biosensor was prepared. Besides that, biosensors were washed with deionised water and were ready to be run in the supporting electrolyte $0.1 \mathrm{M}$ acetate buffer $\mathrm{pH} 4.5$. Others dsDNA biosensors were built under similar conditions (without incubations in degraded TCS) and subsequently measured in buffer solution as controls.

Control solutions and biosensors were made in order to certify that the changes observed in the voltammograms were only due to the interaction effects of the TCS and degraded TCS with dsDNA, poly[G] or poly[A].

These two procedures were adapted from the literature [35].

\section{RESULTS AND DISCUSSION TCS Electrochemical oxidation}

Cyclic and square wave voltammetry

The electrochemical behaviour of TCS was first investigated by CV in a fresh solution of $0.01 \mathrm{mM}$ TCS in $0.1 \mathrm{M}$ phosphate buffer $\mathrm{pH}$ 7.0. Independently of the scan direction (oxidation and reduction) only one 
well-defined anodic peak was observed, in agreement with previous reports [38-40]. Thus, the potential range was selected to positive values for further studies.

The cyclic voltammogram obtained in a fresh solution of $0.01 \mathrm{mM}$ TCS in $0.1 \mathrm{M}$ acetate solution $\mathrm{pH} 3.4$ (Figure $1 \mathrm{~A}$ ) showed the TCS oxidation peak at $\mathrm{E}=+0.82 \mathrm{~V}$ (peak $\mathrm{T}_{1 \mathrm{a}}$ ). No one reverse peak was observed when reversing the scan direction. This shows that the oxidation process of TCS is irreversible [38-40]. In addition, during the first scan, two small reduction peaks appeared (peaks $T_{2 c}$ and $T_{3 c}$ ) at $E=+0.35 \mathrm{~V}$ and $E=+0.23 \mathrm{~V}$, respectively. These products were oxidized, on the second scan, at $E=+0.40 \mathrm{~V}$ and $\mathrm{E}$ $=+0.25 \mathrm{~V}$ (peaks $\mathrm{T}_{2 \mathrm{a}}$ and $\mathrm{T}_{3 \mathrm{a}}$ ). Both peaks are related to the formation of two oxidation products of TCS, which undergo reversible redox process. In addition, there was a decrease of peak $T_{1 a}$ current due to the adsorption of TCS and/or its oxidation products. The similar behaviour was observed in all electrolytes with different $\mathrm{pH}$ values.
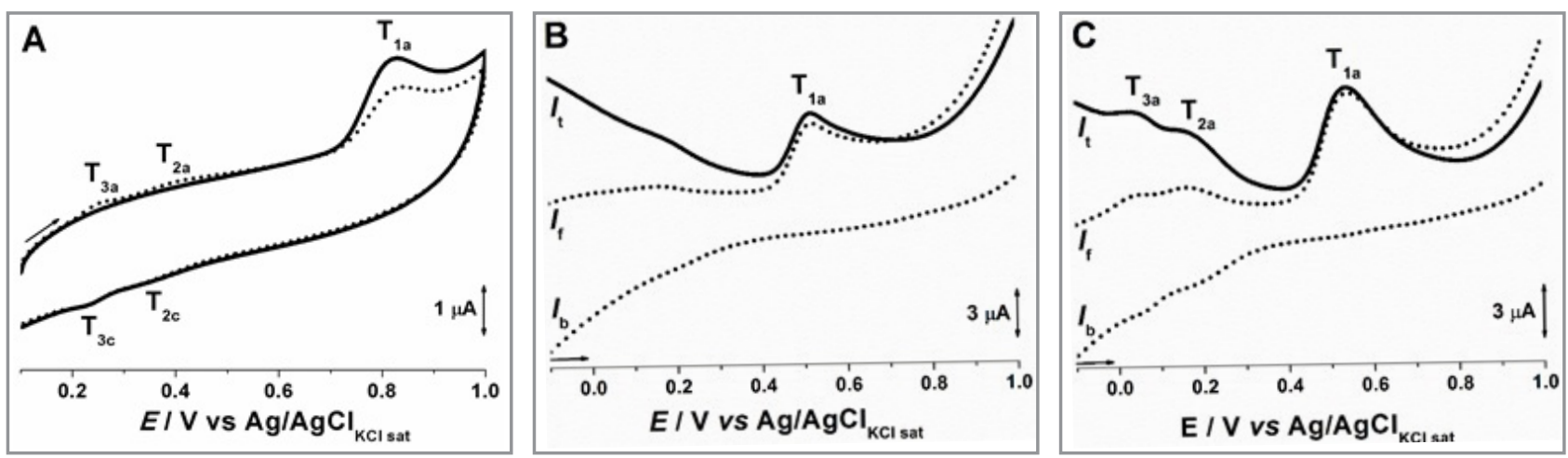

Figure 1. (A) Cyclic voltammograms in a fresh solution of $0.01 \mathrm{mM}$ TCS in $0.1 \mathrm{M}$ acetate solution $\mathrm{pH} 3.4$ : (一) $1^{\text {st }}$ and $(\bullet \cdot) 2^{\text {nd }}$ scans; Step potential of $3 \mathrm{mV}$ and scan rate of $50 \mathrm{mV} \mathrm{s}^{-1}$. SW voltammograms in a fresh solution of $0.01 \mathrm{mM}$ TCS in $0.1 \mathrm{M}$ phosphate buffer $\mathrm{pH} 7.0$ : (B) $1^{\text {st }}$ and C) $2^{\text {nd }}$ scans; Frequency of $50 \mathrm{~Hz}$, potential increment of $2 \mathrm{mV}$ and pulse amplitude of $50 \mathrm{mV}$.

SW voltammetry experiments were also recorded in a fresh solution of $0.01 \mathrm{mM}$ TCS over a wide $\mathrm{pH}$ range. Figure 1B showed the oxidation of the TCS on first scan at $E=+0.51 \mathrm{~V}$ (peak $\mathrm{T}_{1 \mathrm{a}}$ ) in $0.1 \mathrm{M}$ phosphate buffer $\mathrm{pH}$ 7.0. Furthermore, the forward component $\left(I_{\mathrm{f}}\right)$ presented one oxidation peak at the same potential and current intensity as the total current $\left(I_{t}\right)$, while for the backward component $\left(I_{\mathrm{b}}\right)$ no cathodic peak was observed. Therefore, the irreversibility of this reaction was confirmed. On the second scan, the two oxidation peaks at $E=+0.17 \mathrm{~V}\left(\right.$ peak $\left.\mathrm{T}_{2 \mathrm{a}}\right)$ and $E=+0.04 \mathrm{~V}\left(\right.$ peak $\mathrm{T}_{3 \mathrm{a}}$ ) appeared as shown in Figure $1 \mathrm{C}$. Products formed at $\mathrm{T}_{2 \mathrm{a}}$ and $\mathrm{T}_{3 \mathrm{a}}$ peaks are reversibly reduced, since oxidation and reduction peaks for each one - observed in the $I_{\mathrm{f}}$ and $I_{\mathrm{b}}$ - showed the same potentials and currents values. All three peaks presented the same behaviour seen by CV measurements.

\section{Differential Pulse Voltammetry}

The electrochemical behaviour of $0.01 \mathrm{mM}$ TCS based on its effect of $\mathrm{pH}$ in several electrolytes was investigated by DP voltammetry. The voltammograms were obtained immediately after addition of TCS in each electrolyte. Figure $2 \mathrm{~A}$ shows the voltammetric profile for TCS (peak $\mathrm{T}_{1 \mathrm{a}}$ ) recorded in $3.4 \leq \mathrm{pH} \leq$ 12.0. The dependence of the peak $\mathrm{T}_{1 \mathrm{a}}$ potential and current versus $\mathrm{pH}$ is presented in Figure $2 \mathrm{~B}$. The experiments obtained in $\mathrm{pH} \leq 9.2$ buffer solutions showed their oxidation potentials were shifted to more negative values with increasing $\mathrm{pH}$. The slope of the dotted line of $-55 \mathrm{mV}$ per $\mathrm{pH}$ unit for this peak shows that the mechanism of oxidation process involves the same number of electrons and protons [41]. The number of electrons $(n)$ involved in the reaction was estimated using the equation 1 [42], where $\mathrm{R}=8.314$ $\mathrm{J} \mathrm{mol}^{-1} \mathrm{~K}^{-1}, \mathrm{~T}=298 \mathrm{~K}$ and $\mathrm{F}=96500 \mathrm{C} \mathrm{mol}^{-1}$.

$$
W_{1 / 2}=3.52 \mathrm{RT} / n \mathrm{~F} \text { (Equation 1) }
$$


The value of $W_{1 / 2}$ (peak width at half heigth of peak $T_{1 a}$ ) have been found to be $126 \mathrm{mV}$. Thus, for this process the transfer of one electron and one proton occurred in its oxidation mechanism. In $\mathrm{pH}>$ 9.2 buffer solutions, the peak $T_{1 a}$ potential remained constant, indicating that the oxidation process is independent of the $\mathrm{pH}$ value and TCS and/or TCS oxidation products undergo chemical deprotonation after the determining step. Thus, the $p \mathrm{~K}_{\mathrm{a}} \approx 9.2$ for TCS was estimated. Furthermore, the current intensity of the peak $\mathrm{T}_{1 \mathrm{a}}$ decreased with increasing $\mathrm{pH}$, showing a maximum current in $\mathrm{pH} 3.4$.
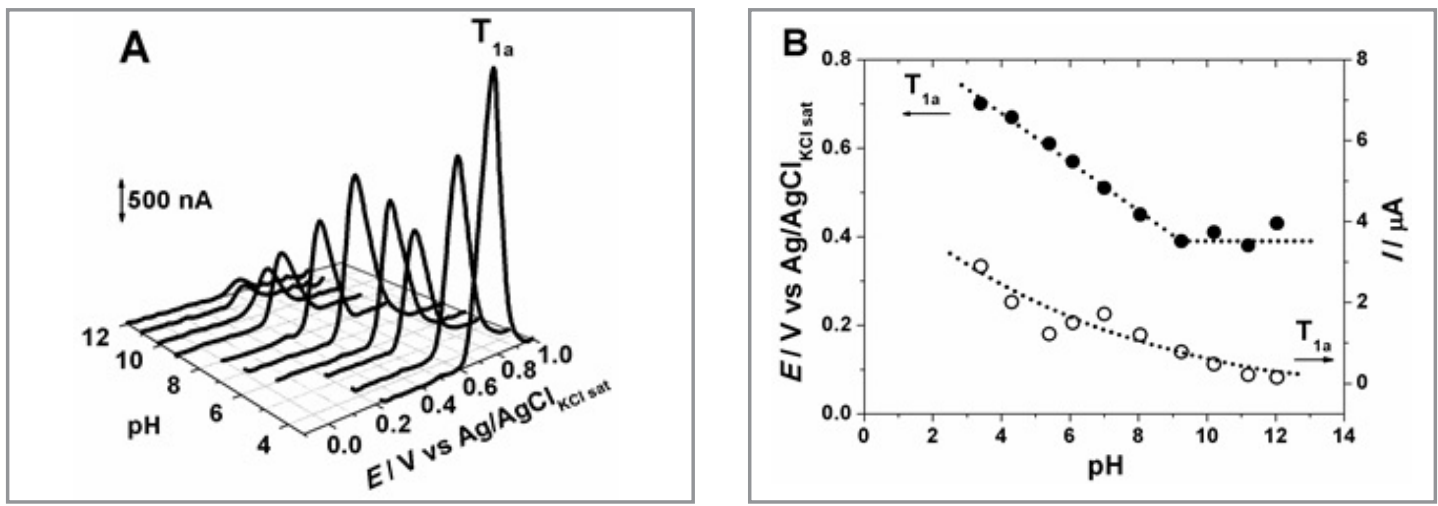

Figure 2. Baseline-corrected DP voltammograms obtained in a fresh solution of $0.01 \mathrm{mM}$ TCS as a function of $\mathrm{pH}$ : A) Plot of $1^{\text {st }}$ scan; B) Plot of $(0) E_{p}$ and $(O) I_{p}$ of peak $T_{1 a}$ vs. $p H$. Pulse amplitude of 50 $\mathrm{mV}$, pulse width of $70 \mathrm{~ms}$, step potential of $2.5 \mathrm{mV}$, interval of time of $500 \mathrm{~ms}$ and scan rate of $5 \mathrm{mV} \mathrm{s}^{-1}$.

Consecutives voltammograms obtained in each supporting electrolyte showed a decrease in the peak $\mathrm{T}_{1 \mathrm{a}}$ current with the increase in the number of scans, and the peak potential shifted to more positive potential values. This behaviour indicates that the electroactive area on the electrode surface has been reduced due to the adsorption of the TCS and/or its oxidation products on it. Moreover, after the second scan two oxidation peaks (peaks $\mathrm{T}_{2 \mathrm{a}}$ and $\mathrm{T}_{3 \mathrm{a}}$ ) appeared as in $\mathrm{CV}$ and $\mathrm{SW}$ voltammetry. On the third scan, both peaks $T_{2 a}$ and $T_{3 a}$ currents increased due to the formation of more oxidation products adsorbed on the electrode surface, as illustrated in Figure 3 for TCS in $0.1 \mathrm{M}$ acetate buffer pH 5.4 solution.

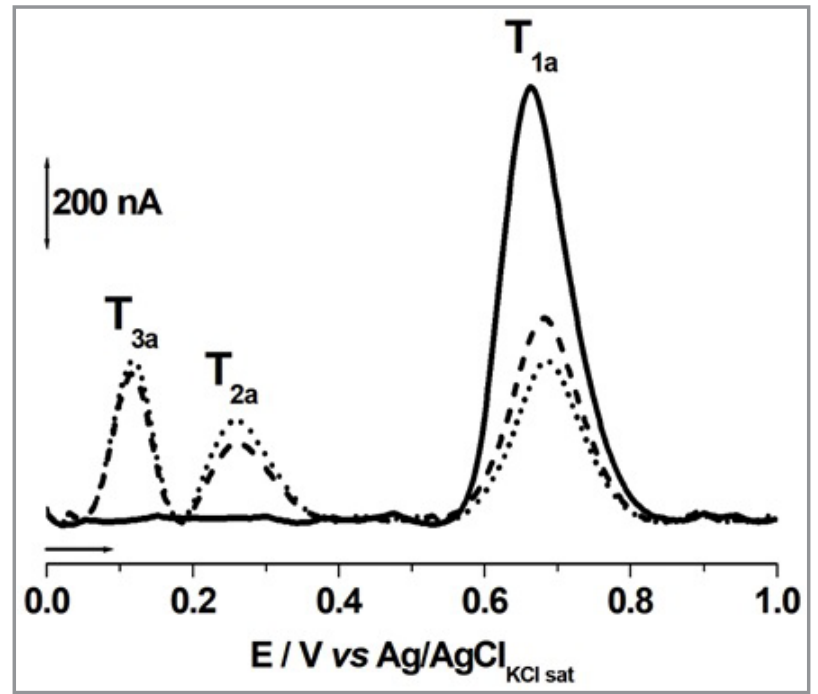

Figure 3. Baseline-corrected DP voltammograms obtained in a fresh solution of $0.01 \mathrm{mM}$ TCS in $0.1 \mathrm{M}$ acetate buffer $\mathrm{pH} 5.4:(-) 1^{\text {st }},(--) 2^{\text {nd }}$ and $(\cdot \bullet) 3^{\text {rd }}$ scans. Pulse amplitude of $50 \mathrm{mV}$, pulse width of $70 \mathrm{~ms}$, step potential of $2.5 \mathrm{mV}$, interval of time of $500 \mathrm{~ms}$ and scan rate of $5 \mathrm{mV} \mathrm{s}^{-1}$. 
The effect of $\mathrm{pH}$ on the oxidation potential of peaks $\mathrm{T}_{2 \mathrm{a}}$ and $\mathrm{T}_{3 \mathrm{a}}$ were performed for the second scan in all supporting electrolytes (Figure 4). For $3.4 \leq \mathrm{pH} \leq 9.2$ the potential of both peaks was dependent of $\mathrm{pH}$, i.e., shifted to less positive values with increasing $\mathrm{pH}$ (Figure 4A). The slope of the dotted line of 62 $\mathrm{mV}$ (peak $\mathrm{T}_{2 \mathrm{a}}$ ) and $56 \mathrm{mV}$ (peak $\mathrm{T}_{3 \mathrm{a}}$ ) show that both oxidation processes involve the transfer of the same number of electrons and protons. Since the values of $W_{1 / 2}=57 \mathrm{mV}$ for peak $\mathrm{T}_{2 \mathrm{a}}$ and $W_{1 / 2}=59 \mathrm{mV}$ for peak $\mathrm{T}_{3 \mathrm{a}}$ the mechanisms of each process take the loss of two electrons and two protons. The intensity of peaks current versus pH presents a maximum of current in $\mathrm{pH} 3.4$ (peak $\mathrm{T}_{2 \mathrm{a}}$ ) and $\mathrm{pH} 7.0$ (peak $\mathrm{T}_{3 \mathrm{a}}$ ) (Figure 4B).
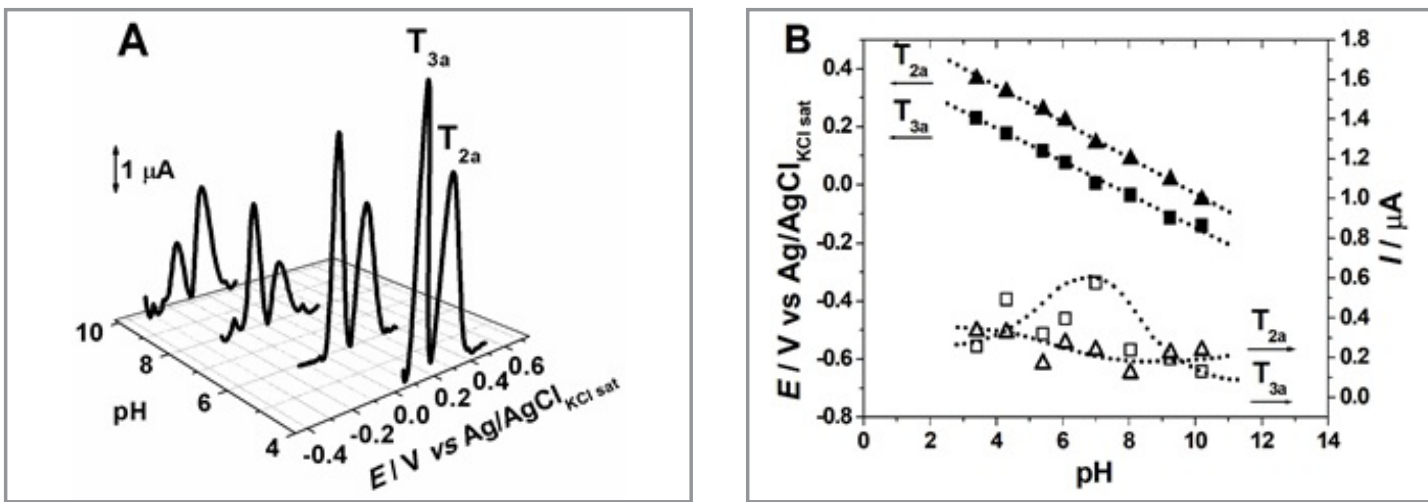

Figure 4. Baseline-corrected DP voltammograms obtained in a fresh solution of $0.01 \mathrm{mM}$ TCS as a function of $\mathrm{pH}$ : A) Plot of $2^{\text {nd }}$ scan; B) Plot of $E_{\mathrm{p}}$ of peaks $(\boldsymbol{\Delta}) \mathrm{T}_{2 a}$ and $(\mathbf{\square}) \mathrm{T}_{3 \mathrm{a}}$ and $I_{p}$ of peaks $(\Delta) T_{2 a}$ and $(\square) T_{3 a}$ vs. pH. Pulse amplitude of $50 \mathrm{mV}$, pulse width of $70 \mathrm{~ms}$, step potential of $2.5 \mathrm{mV}$, interval of time of $500 \mathrm{~ms}$ and scan rate of $5 \mathrm{mV} \mathrm{s}^{-1}$.

\section{Oxidation mechanism of TCS and its oxidation products}

Based on information obtained from previous results, a mechanism of oxidation of TCS and its oxidation products in neutral aqueous solution was proposed (Scheme 2).

As the oxidation of TCS, peak $\mathrm{T}_{1 \mathrm{a}}$, involves the transfer of one electron and one proton, the reaction occurs in the phenolic hydroxyl group of TCS, yielding a phenoxy radical $[38,40,43-45]$, which is stabilized by resonance (Scheme 2A). Among the resonance hybrids, two most stable forms are probably attacked by water through a chemical oxidation reaction, where a hydroxyl group is incorporated into each intermediate, forming two reversible oxidation products of TCS: 2-chloro-5(2,4-dichlorophenoxy)-[1,2]-benzoquinone (peak $\mathrm{T}_{3 \mathrm{a}}$ ) / 2-chloro-5-(2,4-dichlorophenoxy)benzene-1,2diol (peak $\mathrm{T}_{3 \mathrm{c}}$ ); and 2-chloro-5-(2,4-dichlorophenoxy)-[1,4]benzoquinone (peak $\mathrm{T}_{2 \mathrm{a}}$ ) / 2-chloro-5-(2,4dichlorophenoxy)benzene-1,4-diol (peak $\mathrm{T}_{2 \mathrm{c}}$ ), in two electrons and two protons reaction each (Scheme 2B). The redox products (peaks $T_{2 a}-T_{2 c}$ ) were also detected as oxidation products of TCS using GC/ MS and RRLC-MS/MS techniques $[43,44]$. 


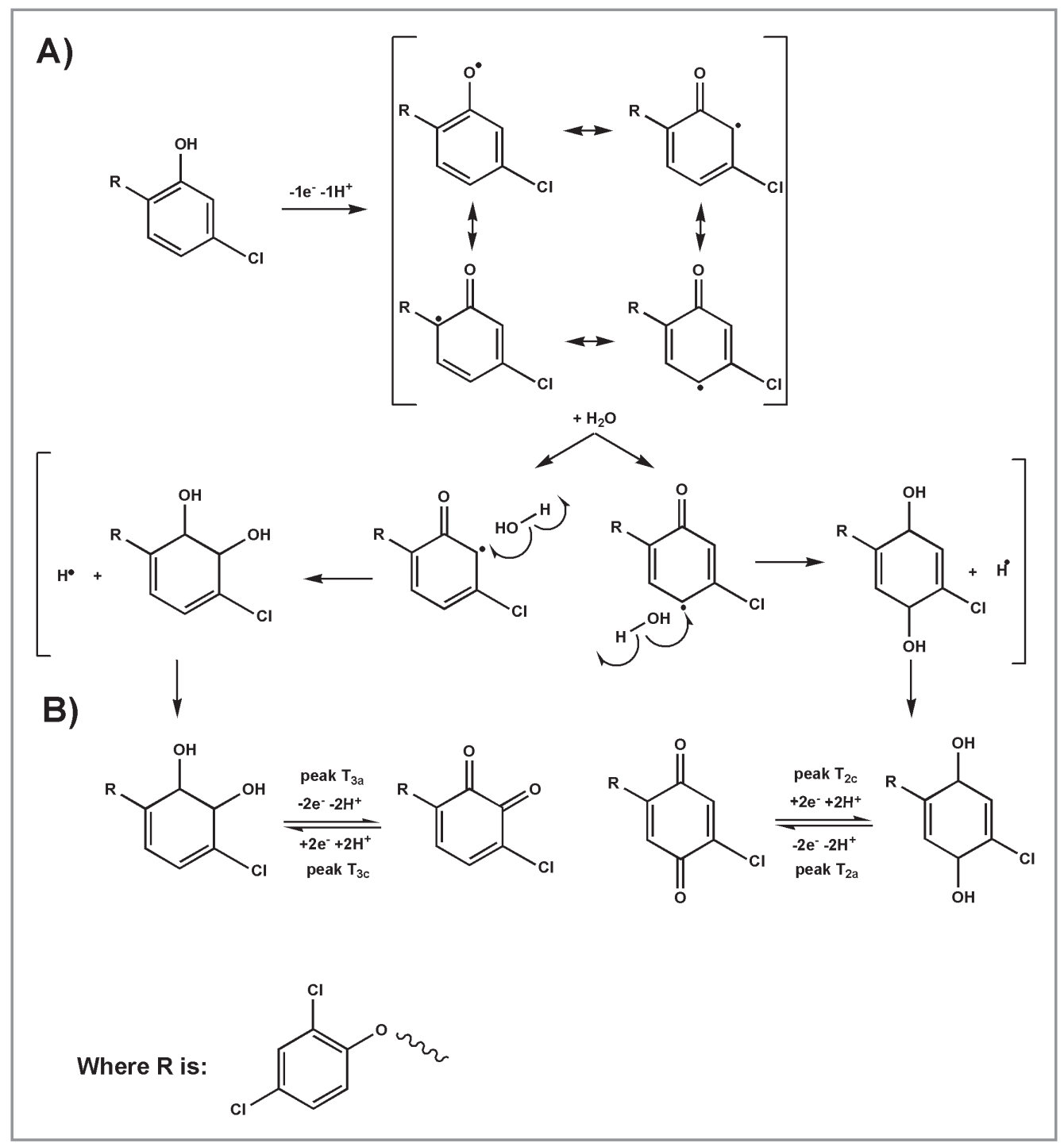

Scheme 2. Proposed mechanism for oxidation of TCS (A) and its oxidation products (B) in neutral aqueous solution.

\section{TCS Degradation process}

\section{Voltammetry analysis}

The TCS degradation was first investigated by DP voltammetry in order to investigate its chemical degradation in aqueous solution. The degradation process of TCS was observed due to changes in the voltammetric profiles of TCS over the incubation time.

Firstly, the oxidation behaviour of TCS in a fresh solution of $0.01 \mathrm{mM}$ TCS in $0.1 \mathrm{M}$ acetate solution pH 3.4 was investigated. Voltammograms recorded showed the peak $T_{1 a}$ at $E=+0.69 \mathrm{~V}$ (Figure 5A). After 24 $\mathrm{h}$ of incubation time, the intensity of this peak current decreased considerably when compared with the peak current for TCS obtained previously. After 30 and 60 days in a buffer solution, the decrease in peak $\mathrm{T}_{1 \mathrm{a}}$ current was proportional to the incubation time. This behaviour corresponds to the decrease in the concentration of TCS in solution and it is attributed to the spontaneous degradation of this antimicrobial compound $[10,46,47]$. No one further peak was observed, indicating that the TCS degradation product(s) formed in solution were not electroactive under conditions studied. 

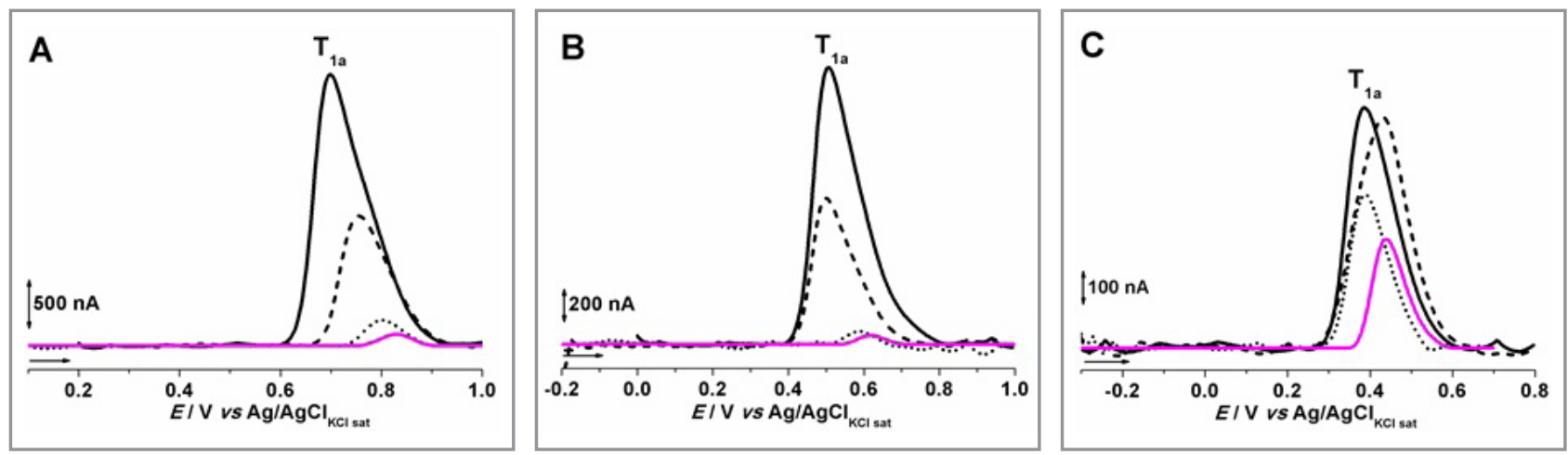

Figure 5. Baseline-corrected DP voltammograms obtained in a fresh solution of $0.01 \mathrm{mM}$ TCS (-) and after $24 \mathrm{~h}(--\cdot), 30(\cdots)$ e 64 days (-) of incubation in: (A) acetate solution $\mathrm{pH} 3.4$; (B) phosphate buffer $\mathrm{pH}$ 7.0 and $(\mathrm{C})$ borax buffer pH 9.2. Pulse amplitude of $50 \mathrm{mV}$, pulse width of $70 \mathrm{~ms}$, step potential of $2.5 \mathrm{mV}$, interval of time of $500 \mathrm{~ms}$ and scan rate of $5 \mathrm{mV} \mathrm{s}^{-1}$.

The behaviour for TCS described above was observed in all supporting electrolytes investigated. Figure $5 \mathrm{~B}$ and $\mathrm{C}$ presented the voltammograms obtained in a neutral and basic medium, respectively.

\section{UV-Vis Spectrophotometry analysis}

The TCS degradation in aqueous solution was also investigated by UV-Vis spectrophotometry. The spectrum registered in a fresh solution of $0.0625 \mathrm{mM}$ TCS in $0.1 \mathrm{M}$ acetate solution $\mathrm{pH} 3.4$ showed one absorption band with a maximum at $\lambda=280 \mathrm{~nm}$ (Figure 6A) in agreement with the literature [46]. A progressive decrease of absorbance was observed after longer incubation times (30 and 64 days), and no other band appeared. After 70 days, the spectrum registered showed the total disappearance of the band.
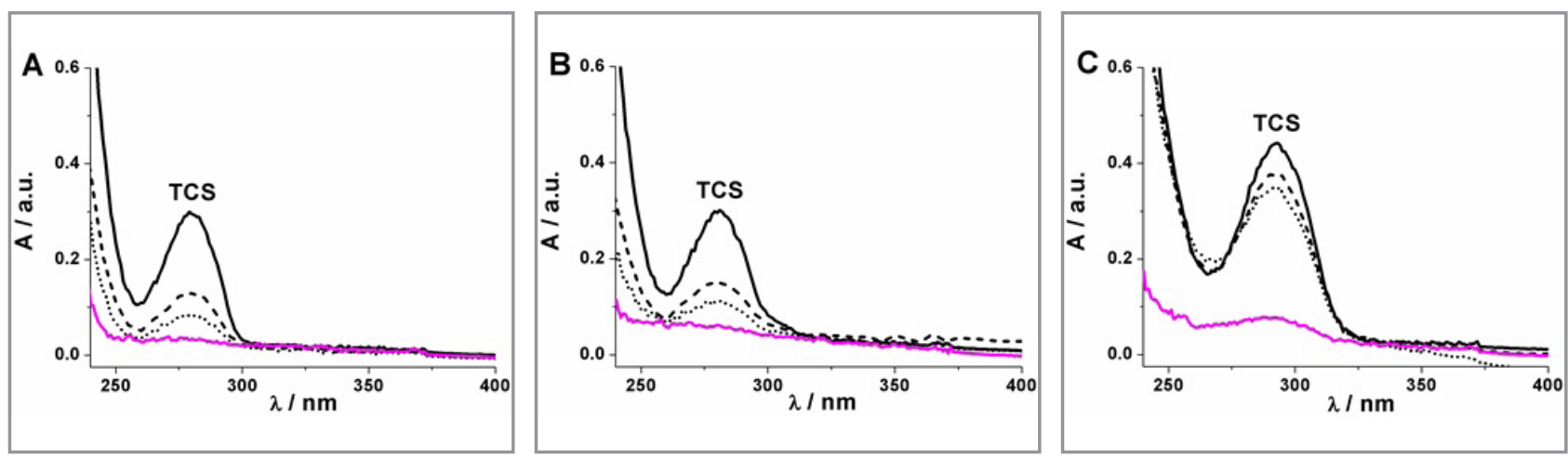

Figure 6. UV-Vis absorption spectra for $0.0625 \mathrm{mM}$ TCS in: (-) $0 \mathrm{~h}$ and after (---) 30, (•••) 64 and (-) 70 days of incubation in: $(\mathrm{A})$ acetate solution $\mathrm{pH} 3.4$; (B) phosphate buffer $\mathrm{pH} 7.0$ and $(\mathrm{C})$ borax buffer $\mathrm{pH} 9.2$.

The same behaviour was observed for TCS in $0.1 \mathrm{M}$ phosphate buffer $\mathrm{pH} 7.0$ and $0.1 \mathrm{M}$ borax buffer pH 9.2 (Figure 6B and C). However, in alkaline conditions, the TCS absorption band shifted to $\lambda=291 \mathrm{~nm}$ [46]. Furthermore, after 70 days of incubation, one absorption band was still detected in basic medium.

Previously, it has been reported that the TCS has an absorption band at $\lambda=280 \mathrm{~nm}$ for the molecular form and at $\lambda=292 \mathrm{~nm}$ for the anionic form in a study carried out on the direct phototransformation of TCS in surface waters [48]. In addition, the anionic form has higher molar absorptivity than the molecular form and is found in greater amounts in alkaline solutions. This was observed in our experiments (Figure 6C) which shows higher absorption bands for the TCS and their displacement for a longer wavelength when compared to solutions with lower $\mathrm{pH}$ values. TCS is also long known to be more photochemically labile under basic conditions [10] and the transformation of its anionic form under sunlight is much faster 
Silva, E. H. C.; Lopes, I. C.; Bruzaca, E. E. S.; de Carvalho, P. A. V.; Tanaka, A. A.

than the transformation of the molecular form [48]. Thus, in this work, we can state that the spontaneous degradation of TCS observed in the electrolytes studied was more pronounced in alkaline medium.

The spectrophotometric experiments are in accordance with DP voltammetry, showing that the TCS undergoes chemical degradation in aqueous solution.

\section{Effects of TCS on DNA}

The effects of TCS on DNA were studied through the interaction in situ of TCS and degraded TCS with dsDNA by DP voltammetry, in order to investigate conformational changes in the structure of dsDNA caused by antibacterial agent and/or degradation products.

\section{Interaction of TCS and degraded TCS with dsDNA, POLY[G] and POLY[A] Incubated Solutions}

The interaction of TCS and degraded TCS with dsDNA was first investigated in incubated solutions as a function of the incubation time (Figure $7 \mathrm{~A}$ and $\mathrm{B}$ ).
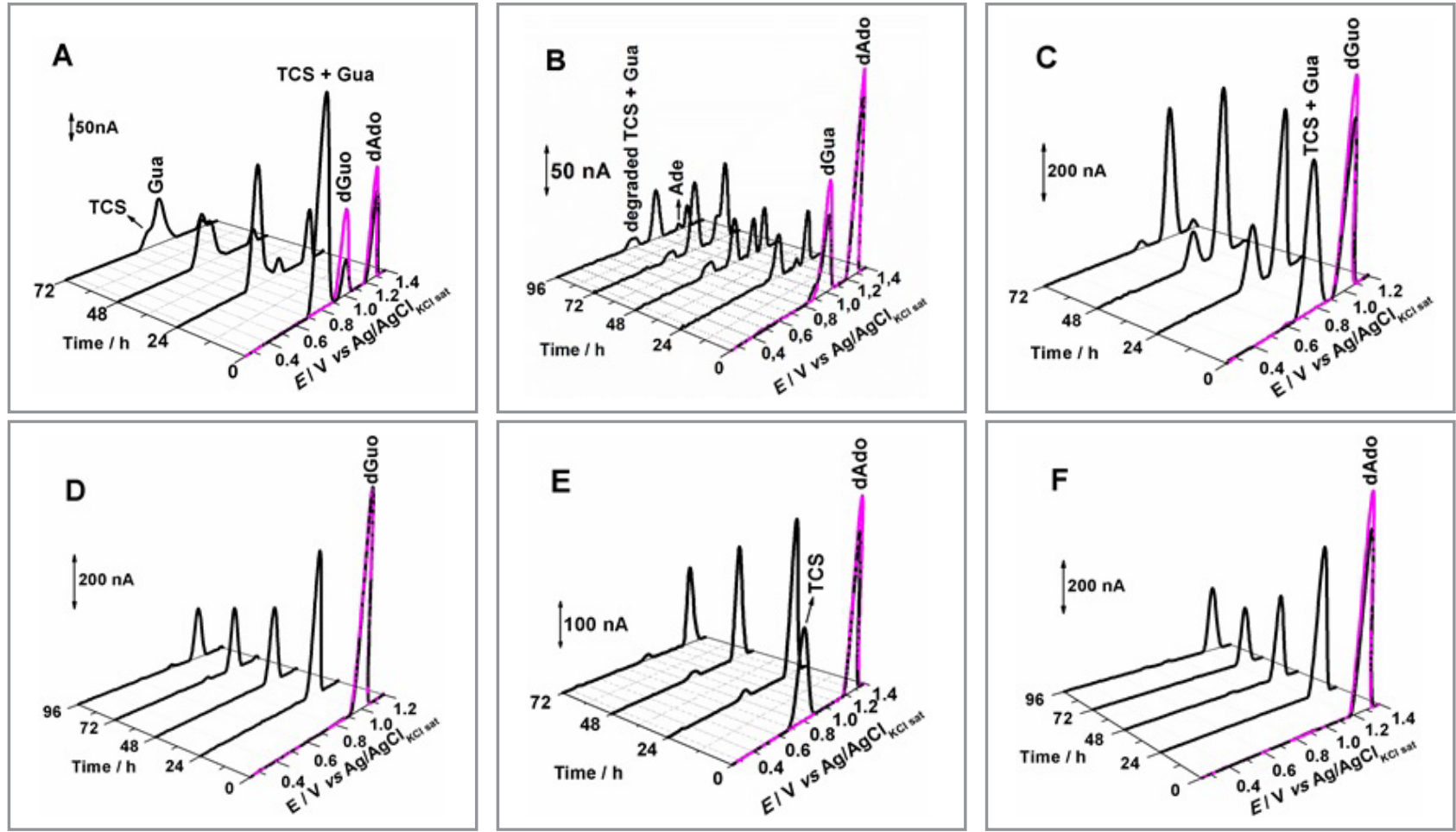

Figure 7. Baseline-corrected DP voltammograms obtained in $0.1 \mathrm{M}$ acetate buffer solution $\mathrm{pH}$ 4.5: (-) control solutions and (-) incubated solutions as: (A) $5 \mu \mathrm{M} \mathrm{TCS}+100 \mu \mathrm{g} \mathrm{mL}-1$ dsDNA; (B) $5 \mu \mathrm{M}$ degraded TCS + 100 $\mu \mathrm{g} \mathrm{mL}{ }^{-1}$ dsDNA; (C) $5 \mu \mathrm{M}$ TCS + $100 \mu \mathrm{g} \mathrm{mL} \mathrm{m}^{-1}$ Poly[G]; (D) $5 \mu \mathrm{M}$ degraded TCS + $100 \mu \mathrm{gL}^{-1}$ Poly[G]; (E) 5 $\mu \mathrm{M}$ TCS $+100 \mu \mathrm{g} \mathrm{mL}-1$ Poly[A] and (F) $5 \mu \mathrm{M}$ degraded TCS $+100 \mu \mathrm{gL}^{-1}$ Poly[A]. Pulse amplitude of $50 \mathrm{mV}$, pulse width of $70 \mathrm{~ms}$, step potential of $2.5 \mathrm{mV}$, interval of time of $500 \mathrm{~ms}$ and scan rate of $5 \mathrm{mV} \mathrm{s}^{-1}$.

$100 \mu \mathrm{g} \mathrm{mL} \mathrm{L}^{-1} \mathrm{dsDNA}$ solution was registered in $0.1 \mathrm{M}$ acetate buffer $\mathrm{pH} 4.5$ as a control and presented the desoxyguanosine (dGuo) peak, at $E=+0.98 \mathrm{~V}$, and desoxyadenosine (dAdo) peak, at $E=+1.25$ $\mathrm{V}$, [49] (Figure 7A). Right after mixing $5 \mu \mathrm{M}$ TCS with dsDNA in solution, a marked decrease in dsDNA peaks was observed. This behavior indicates that TCS interacted with dsDNA causing condensation of the double helix chain, leading to the difficulty in oxidizing nitrogenous bases on the electrode surface. A further peak at $E=+0.78 \mathrm{~V}$ was detected in the voltammogram, corresponding to the oxidation of TCS and possible free guanine (Gua) mixed in solution, as both are oxidized separately to similar potentials, $E=+$ $0.78 \mathrm{~V}$ and $E=+0.85 \mathrm{~V}$ [34], respectively. Over incubation time dsDNA peaks drastically decreased and 
after 48 and $72 \mathrm{~h}$ the dGuo peak disappeared. In addition, the TCS peak decreased, due to its degradation in solution, and the Gua peak stood out, due to more Gua formation in solution. However, no oxidative damage to dsDNA was observed in the voltammograms, since the biomarkers of guanine (8-oxoGua) and adenine (2,8-oxoAde), at $E=+0.45 \mathrm{~V}$, [35] was not detected under these conditions.

For the degraded TCS-dsDNA solution interaction, the study showed the dsDNA peaks at $E=+0.99 \mathrm{~V}$ (dGuo) and $E=+1.26 \mathrm{~V}$ (dAdo) for the control experiment (100 $\mu \mathrm{g} \mathrm{mL}^{-1} \mathrm{dsDNA}$ solution) (Figure 7B). Soon after adding $5 \mu \mathrm{M}$ degraded TCS to the dsDNA solution, dsDNA peaks decreased showing an interaction of degraded TCS with the double helix structure. After longer incubation times, new peaks were seen at + $0.79 \mathrm{~V}$ and $+1.16 \mathrm{~V}$, corresponding to the oxidation of (degraded TCS + Gua) and free adenine (Ade) [34] released from dsDNA, respectively. No peak associated to 8-oxoGua and/or 2,8-oxoAde biomarkers was detected in these experiments.

In order to obtain more information about the interaction of TCS and degraded TCS with dsDNA occurred, investigations involving homopolynucleotides (poly [G] and poly $[A]$ ) in incubated solutions were conducted at different incubation times (Figure 7C and D) and (Figure 7E and F), respectively.

$100 \mu \mathrm{g} \mathrm{mL}-1$ poly[G] solution in $0.1 \mathrm{M}$ acetate buffer $\mathrm{pH} 4.5$ was run as a control and exhibited one peak at $E=+1.01 \mathrm{~V}$, corresponding to the oxidation of dGuo residues, which decreased with increasing incubation time with $5 \mu \mathrm{M}$ TCS (Figure 7C). One new peak occurred at $E=+0.74 \mathrm{~V}$ immediately after adding TCS to the buffer. This peak corresponding to the oxidation of (TCS + Gua) in solution, which reduced after longer incubation times, due to the TCS degradation. On the other hand, the voltammogram registered for $100 \mu \mathrm{g} \mathrm{mL}^{-1}$ poly[A] solution as a control showed one peak at $E=+1.26 \mathrm{~V}$, related to the oxidation of dAdo residues (Figure 7E). This peak decreased with increasing incubation time in $5 \mu \mathrm{M}$ TCS solution and the TCS peak at $E=+0.88 \mathrm{~V}$ was detected in all voltammograms. Moreover, no 8-oxoGua or 2,8-oxoAde peak was observed under these conditions, indicating that no dsDNA oxidative damage was detected.

In Figure 7D, a solution of $100 \mu \mathrm{g} \mathrm{mL}^{-1}$ poly[G] in $0.1 \mathrm{M}$ acetate buffer $\mathrm{pH} 4.5$ (control) showed the dGuo peak at $E=+0.99 \mathrm{~V}$. Between 24 and $96 \mathrm{~h}$ of incubation with $5 \mu \mathrm{M}$ degraded TCS this peak decreased successively. For the degraded TCS-poly[A] solution interaction, the voltammogram revealed the dAdo peak at $E=+1.25 \mathrm{~V}$ (Figure 7F) which also decreased over the incubation time with $5 \mu \mathrm{M}$ degraded TCS, compared to the peak for the control poly[A] solution. No oxidative damage to dsDNA was noticed.

\section{Interaction of degraded TCS with dsDNA biosensors}

Degraded TCS-dsDNA interaction was also investigated by incubating dsDNA biosensors in $5 \mu \mathrm{M}$ degraded TCS solutions in different interaction times (Figure 8).

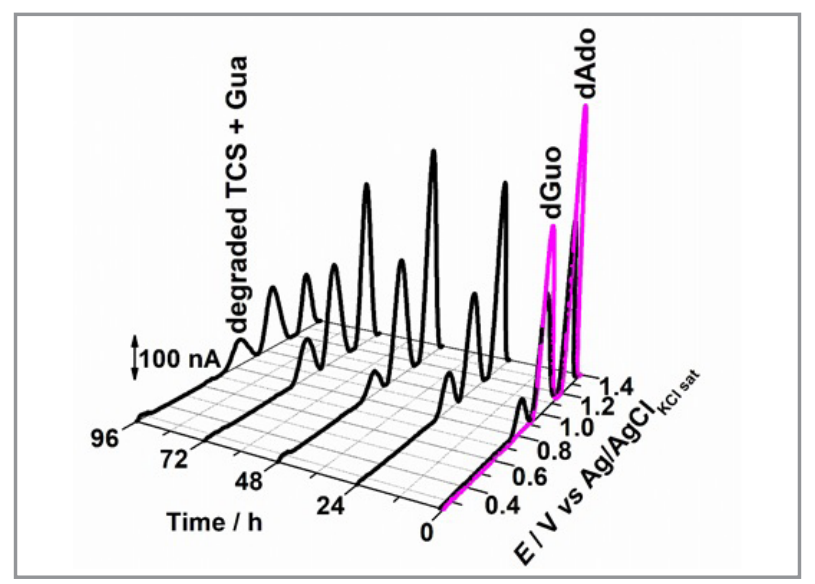

Figure 8. Baseline-corrected DP voltammograms obtained in $0.1 \mathrm{M}$ acetate buffer $\mathrm{pH}$ 4.5: $100 \mu \mathrm{gL}^{-1}$ dsDNA biosensor (-) control and incubated with: (A) $5 \mu \mathrm{M}$ degraded TCS (-). Pulse amplitude of 50 $\mathrm{mV}$, pulse width of $70 \mathrm{~ms}$, step potential of $2.5 \mathrm{mV}$, interval of time of $500 \mathrm{~ms}$ and scan rate of $5 \mathrm{mV} \mathrm{s}^{-1}$. 
For the control biosensor dsDNA, the nucleosides peaks were detected at $E=+1.02 \mathrm{~V}$ (dGuo) and $E=+$ $1.28 \mathrm{~V}$ (dAdo) (Figure 8). These peaks decreased during the incubation period, indicating the degradation products of TCS interacted with dsDNA leading to the condensation of double helix molecule. After $1 \mathrm{~h}$ of interaction an additional peak was seen at $E=+0.84 \mathrm{~V}$, associated to the oxidation of (degraded TCS + Gua). It is known that electrode surface is completely covered by dsDNA film and biosensor response is due only to the interaction of the compound with dsDNA, consequently preventing non-specific adsorption [50]. However, in this case, this peak is indicative of a possible intercalation of degraded TCS in the DNA structure, since the peak current practically remains constant until $96 \mathrm{~h}$ of incubation instead of increasing due to the increased concentration of the dsDNA released Gua. No oxidative damage to dsDNA was observed, since the 8-oxoGua and 2,8-oxoAde biomarkers was not detected.

These results are in agreement with the analysis obtained using dsDNA incubated solutions.

\section{CONCLUSIONS}

This research provides a complete electrochemical study of antimicrobial compound TCS at a glassy carbon electrode, as well as a novel study of its spontaneous degradation in aqueous solution. TCS undergoes irreversible electrochemical oxidation through the transfer of one electron and one proton and with the formation of two oxidation products reversibly oxidized, involving the loss of two electrons and two protons each. A remarkable chemical degradation of TCS in a time-dependent manner was observed in all electrolytes studied with faster degradation in alkaline medium. This work also explains novel evidences that the TCS and degraded TCS interact in situ with dsDNA, leading to the condensation of the structure of the DNA molecule and release of nitrogenous bases: guanine (by TCS and degraded TCS) and adenine (by degraded TCS). Furthermore, the degraded TCS possibly intercalated in the double-stranded DNA. However, no oxidative damage to dsDNA by TCS or its degradation product(s) was detected under the experimental conditions shown. Thus, this research brings interesting findings that may lead to a clearer understanding of the action mechanism of TCS in the DNA in the future.

\section{Conflicts of interest}

The authors declare that have no conflicts of interest to disclose.

\section{Acknowledgements}

We sincerely thank funding agencies: FAPEMA fellow-Brazil (BIC-02375/14), CNPq fellow-Brazil (313627/2013-4), CNPq-Brazil (103256/2014-8), CAPES-Brazil (Finance Code 001), CNPq (Project 400578/2013-1) and INCT de Bioanalitica (Project CNPq/INCT 465389/2014-7).

\section{REFERENCES}

1. Solá-Gutiérrez, C.; Schröder, S.; San-Román, M. F.; Ortiz, I. J. Environ. Manage., 2020, 260, 110101 (https://doi.org/10.1016/j.jenvman.2020.110101).

2. Quan, B.; Li, X.; Zhang, H.; Zhang, C.; Ming, Y.; Huang, Y.; Xi, Y.; Weihua, X.; Yunguo, L.; Tang, Y. Chem. Eng. J., 2019, 378, 122185 (https://doi.org/10.1016/j.cej.2019.122185).

3. Ley, C.; Sundaram, V.; de la Luz Sanchez, M.; Desai, M., Parsonnet, J. PLoS One, 2018, 13 (6), pp 1-15 (https://doi.org/10.1371/journal.pone.0199298).

4. Jones, R. D.; Jampani, H. B.; Newman, J. L.; Lee, A. S. Am. J. Infect. Control., 2000, 28, pp 184-196 (https://doi.org/10.1067/mic.2000.102378).

5. Luo, Z.; He, Y.; Zhi, D.; Luo, L.; Sun, Y.; Khan, E.; Wang, L.; Peng, Y.; Zhou, Y.; Tsang, D.C.W. Sci. Total Environ., 2019, 696, 133990 (https://doi.org/10.1016/j.scitotenv.2019.133990).

6. Ahmed, I.; Boulton, A. J.; Rizvi, S.; Carlos, W.; Dickenson, E.; Smith, N. A.; Reed, M. BMJ Open, 2019, 9, pp 1-12 (https://doi.org/10.1136/bmjopen-2019-029727).

7. Lee, J. D.; Lee, J. Y.; Kwack, S. J.; Shin, C. Y.; Jang, H. J.; Kim, H. Y.; Kim, M. K.; Seo, D. W.; Lee, B. M.; Kim, K. B. Toxicol. Res., 2019, 35, pp 137-154 (https://doi.org/10.5487/TR.2019.35.2.137). 
8. Chen, X.; Zhuang, J.; Bester, K. Appl. Microbiol. Biotechnol., 2018, 102, pp 5403-5417 (https://doi. org/10.1007/s00253-018-9029-y).

9. Zhang, Z.; Wang, X.; Xue, Y.; Li, H.; Dong, W. Chem. Eng. J., 2015, 263, pp 186-193 (https://doi. org/10.1016/j.cej.2014.11.048).

10. Kliegman, S.; Eustis, S. N.; Arnold, W. A.; McNeill, K. Environ. Sci. Technol., 2013, 47, pp 6756-6763 (https://doi.org/10.1021/es3041797).

11. Singer, H.; Müller, S.; Tixier, C.; Pillonel, L. Environ. Sci. Technol., 2002, 36, pp 4998-5004 (https:// doi.org/10.1021/es025750i).

12. Latch, D. E.; Packer, J. L.; Stender, B. L.; VanOverbeke, J.; Arnold, W. A.; McNeill, K. Environ. Toxicol. Chem., 2005, 24, pp 517-525 (https://doi.org/10.1897/04-243R.1).

13. Lindström, A.; Buerge, I. J.; Poiger, T.; Bergqvist, P. A.; Müller, M. D.; Buser, H. R. Environ. Sci. Technol., 2002, 36, pp 2322-2329 (https://doi.org/10.1021/es0114254).

14. Rule, K. L.; Ebbett, V. R.; Vikesland, P. J. Environ. Sci. Technol., 2005, 39, pp 3176-3185 (https://doi. org/10.1021/es048943+).

15. Wang, S.; Wang, J. Environ. Technol. (United Kingdom), 2017, 39, pp 1115-1122 (https://doi.org/10.1 080/09593330.2017.1321692).

16. Yueh, M.; Tukey, R. H. Annu. Rev. Pharmacol. Toxicol., 2016, 56, pp 251-272 (https://doi. org/10.1146/annurev-pharmtox-010715-103417).

17. Schweizer, H. P. FEMS Microbiol. Lett., 2001, 202, pp 1-7 (https://doi.org/10.1016/S03781097(01)00273-7).

18. Drury, B.; Scott, J.; Rosi-Marshall, E. J.; Kelly, J. J. Environ. Sci. Technol., 2013, 47, pp 8923-8930 (https://doi.org/10.1021/es401919k).

19. Knust, K. N.; Foley, M. P.; Mubarak, M. S.; Skljarevski, S.; Raghavachari, K.; Peters, D. G. J. Electroanal. Chem., 2010, 638, pp 100-108 (https://doi.org/10.1016/j.jelechem.2009.10.012).

20. Zeng, L.; Ma, H.; Pan, S.; You, J.; Zhang, G.; Yu, Z.; Sheng, G.; Fu, J. Toxicol. Vitr., 2016, 34, pp 3544 (https://doi.org/10.1016/j.tiv.2016.03.002).

21. Anger, C. T.; Sueper, C.; Blumentritt, D. J.; McNeill, K.; Engstrom, D. R.; Arnold, W. A. Environ. Sci. Technol., 2013, 47, pp 1833-1843 (https://doi.org/10.1021/es3045289).

22. Fiss, E. M.; Rule, K. L.; Vikesland, P. J.; Environ. Sci. Technol., 2007, 41, pp 2387-2394 (https://doi. org/10.1021/es062227I).

23. Peropadre, A.; Blanco, L.; Freire, P. F.; Repetto, G.; Hazen, M. Toxicol. Lett., 2016, 258S, p S248 (https://doi.org/10.1016/j.toxlet.2016.06.1880).

24. Ma, H.; Zheng, L.; Li, Y.; Pan, S.; Hu, J.; Yu, Z.; Zhang, G.; Sheng, G.; Fu, J. Chemosphere, 2013, 90, pp 1023-1029 (https://doi.org/10.1016/j.chemosphere.2012.07.063).

25. Jurewicz, J.; Radwan, M.; Wielgomas, B.; Kałużny, P.; Klimowska, A.; Radwan, P.; Hanke, W. Environ. Sci. Pollut. Res., 2018, 25, pp 5484-5490 (https://doi.org/10.1007/s11356-017-0866-5).

26. Rodricks, J. V.; Swenberg, J. A.; Borzelleca, J. F.; Maronpot, R. R.; Shipp, A. M. Crit. Rev. Toxicol., 2010, 40, pp 422-484 (https://doi.org/10.3109/10408441003667514).

27. Falisse, E.; Ducos, B.; Stockwell, P. A.; Morison, I. M.; Chatterjee, A.; Silvestre, F. Environ. Pollut., 2018, 243, pp 1867-1877 (https://doi.org/10.1016/j.envpol.2018.10.004).

28. Lin, D.; Li, Y.; Zhou, Q.; Xu, Y.; Wang, D. Ecotoxicology, 2014, 23, pp 1826-1832 (https://doi. org/10.1007/s10646-014-1320-9).

29. Motia, S.; Tudor, I. A.; Ribeiro, P. A.; Raposo, M.; Bouchikhi, B.; El Bari, N. Sci. Total Environ., 2019, 664, pp 647-658 (https://doi.org/10.1016/j.scitotenv.2019.01.331).

30. Mpupa, A.; Mashile, G. P.; Nomngongo, P. N. Open Chem., 2017, 15, pp 255-262 (https://doi. org/10.1515/chem-2017-0032).

31. Atar, N.; Eren, T.; Yola, M. L.; Wang, S. Sensors Actuators, B Chem., 2015, 216, pp 638-644 (https:// doi.org/10.1016/j.snb.2015.04.076). 
32. Kobusińska, M. E; Witt, M.; Łęczyński, L.; Niemirycz, E. Int. J. Environ. Anal. Chem., 2018, 98, pp 453-476 (https://doi.org/10.1080/03067319.2018.1477135).

33. Oliveira, S. C. B.; Corduneanu, O.; Oliveira-Brett, A. M. Bioelectrochemistry, 2008, 72, pp 53-58 (https://doi.org/10.1016/j.bioelechem.2007.11.004).

34. Bruzaca, E. E. S.; Lopes, I. C.; Silva, E. H. C.; Carvalho, P. A. V.; Tanaka A. A. Microchem. J., 2017, 133, pp 81-89 (https://doi.org/10.1016/j.microc.2017.03.030).

35. Carvalho, P. A. V. de; Lopes, I. C.; Silva, E. H. C.; Bruzaca, E. E. S.; Alves, H. J.; Lima, M. I. S.; Tanaka, A. A. J. Pharm. Biomed. Anal., 2019, 176, 112786 (https://doi.org/10.1016/j. jpba.2019.112786).

36. Fasman, G. D. Handbook of Biochemistry and Molecular Biology, 3rd ed., Cleveland, 1975.

37. Lopes, I. C.; Santos, P. V. F.; Diculescu, V. C.; Peixoto, F. M. P.; Araújo, M. C. U.; Tanaka, A. A.; Oliveira-Brett, A. M. Analyst, 2012, 137, pp 1904-1912 (https://doi.org/10.1039/c2an16017j).

38. Vidal, L.; Chisvert, A.; Canals, A.; Psillakis, E.; Lapkin, A.; Acosta, F.; Edler, K. J.; Holdaway, J. A.; Marken, F. Anal. Chim. Acta, 2008, 616, pp 28-35 (https://doi.org/10.1016/j.aca.2008.04.011).

39. Dai, H.; Xu, G.; Gong, L.; Yang, C.; Lin, Y.; Tong, Y.; Chen, J.; Chen, G. Electrochim. Acta, 2012, 80, pp 362-367 (https://doi.org/10.1016/j.electacta.2012.07.032).

40. Moyo, M.; Florence, L. R.; Okonkwo, J. O. Sensors Actuators, B Chem., 2015, 209, pp 898-905 (https://doi.org/10.1016/j.snb.2014.12.059).

41. Smith, E.T. Anal. Chim. Acta, 2006, 572, pp 259-264 (https://doi.org/10.1016/j.aca.2006.05.025).

42. Brett, C. M. A.; Brett, A. M. O. Electrochemistry: Principles, Methods, and Applications, 1st ed., Oxford University Press, Oxford, 1993.

43. Zhang, H.; Huang, C. H. Environ. Sci. Technol.; 2003, 37, pp 2421-2430 (https://doi.org/10.1021/ es026190q).

44. Yang, B.; Ying, G. G.; Zhao, J. L.; Zhang, L. J.; Fang, Y. X.; Nghiem, L. D. J. Hazard. Mater., 2011, 186, pp 227-235 (https://doi.org/10.1016/j.jhazmat.2010.10.106).

45. Dai, H.; Xu, G.; Gong, L.; Yang, C.; Lin, Y.; Tong, Y.; Chen, J.; Chen, G. Electrochim. Acta, 2012, 80, pp 362-367 (https://doi.org/10.1016/j.electacta.2012.07.032).

46. Wong-Wah-Chung, P.; Rafqah, S.; Voyard, G.; Sarakha, M. Photobiol. A Chem., 2007, 191, pp 201208 (https://doi.org/10.1016/j.jphotochem.2007.04.024).

47. Son, H. S.; Choi, S. B.; Zoh, K. D.; Khan, E. Water Sci. Technol., 2007, 55, pp 209-216 (https://doi. org/10.2166/wst.2007.034).

48. Tixier, C.; Singer, H. P.; Canonica, S.; Müller, S. R. Environ. Sci. Technol., 2002, 36, pp 3482-3489 (https://doi.org/10.1021/es025647t).

49. Buoro, R. M.; Lopes, I. C.; Diculescu, V. C.; Serrano, S. H. P.; Lemos, L.; Oliveira-Brett, A. M. Bioelectrochemistry, 2014, 99, pp 40-45 (https://doi.org/10.1016/j.bioelechem.2014.05.005).

50. Oliveira, S. C. B.; Oliveira-Brett, A. M. Comb. Chem. High Throughput Screen., 2010, 13, pp 628-640 (https://doi.org/10.2174/1386207311004070628). 